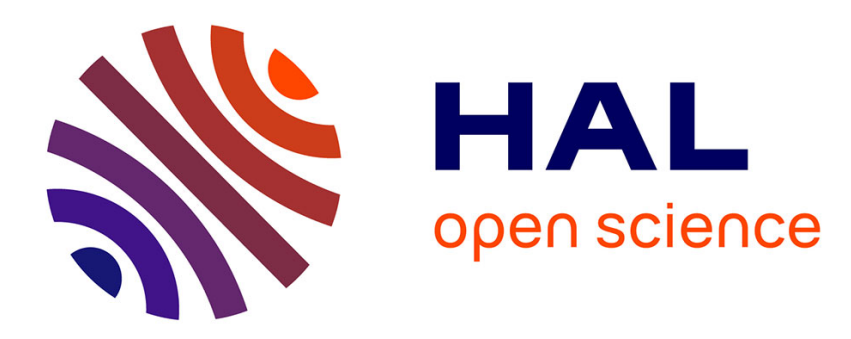

\title{
Silicon Carbide Coating for Carbon Materials Produced by a Pack-Cementation Process
}

\author{
O. Paccaud, A. Derré
}

\section{To cite this version:}

O. Paccaud, A. Derré. Silicon Carbide Coating for Carbon Materials Produced by a PackCementation Process. Journal de Physique IV Proceedings, 1995, 05 (C5), pp.C5-135-C5-142. 10.1051/jphyscol:1995514 . jpa-00253839

\section{HAL Id: jpa-00253839 https://hal.science/jpa-00253839}

Submitted on 1 Jan 1995

HAL is a multi-disciplinary open access archive for the deposit and dissemination of scientific research documents, whether they are published or not. The documents may come from teaching and research institutions in France or abroad, or from public or private research centers.
L'archive ouverte pluridisciplinaire HAL, est destinée au dépôt et à la diffusion de documents scientifiques de niveau recherche, publiés ou non, émanant des établissements d'enseignement et de recherche français ou étrangers, des laboratoires publics ou privés. 


\title{
Silicon Carbide Coating for Carbon Materials Produced by a Pack-Cementation Process
}

\author{
O. Paccaud and A. Derré(1)
}

CNRS, Centre de Recherche Paul Pascal, avenue Schweitzer, 33600 Pessac, France

\begin{abstract}
A pack-cementation process has been developed in order to produce SiC coating on carbon materials. At high temperature gaseous silicon monoxide generated from a $\mathrm{SiC}_{-} \mathrm{SiO}_{2}$ powders mixture reacts with carbon substrate by converting the outer surfaces into silicon carbide. The correlation between density measurements and thermochemical calculations allows to determine the reaction path mechanism for the $\mathrm{SiC}$ layer formation. Iridium marker experiments are proposed to localize the substrate initial surface position after cementation. It is thus established that the growth originates at the substrate-film interface. Using an original approach, it is pointed out that the growth results from a gaseous mechanism which carries the reaction silicon species through the $\mathrm{SiC}$ layer to the substrate. X-ray diffraction, transmission electron microscopy and density measurement permit some description of the cemented layer structure: the cementation leads to a fine porous coating of $\beta$-SiC. Polytypic stacking faults probably exist whose frequency qualitatively increases from the outer to the inner surface of the film.
\end{abstract}

\section{INTRODUCTION}

High temperature composite materials are needed in several aerospace applications. The physico-chemical properties of carbon-carbon composites generally meet the desired requirements as toughness, low density, thermal stability or thermal shock resistance associated with low thermal expansion behaviour. A notable drawback consists in the limited resistance to oxidation of carbonaceous materials which react with oxygen to form volatile compounds at temperatures as low as $500^{\circ} \mathrm{C}$.

For higher temperatures, the current technology relies on a suitable outer ceramic coating that produces oxidation protective material through thermochemical reaction with oxygen. The most promising is silicon carbide $\mathrm{SiC}$ and the most often used process consists on chemical vapor deposition (CVD). Unfortunately, because of the thermal expansion mismatch, cracks develop during thermal cycling and poor adhesion is generally obtained. Therefore, one goal of this work is to develop an improved coating.

(1) author to whom correspondence should be addressed 
A lot of gaseous precursors have been already used to synthesize SiC by CVD [1-3]. Actual trends involve organometallic precursors, the most common being certainly the trichloromethylsilane $\mathrm{Cl}_{3} \mathrm{SiCH}_{3}$ appropriately diluted in hydrogen gas.

More and more authors try to create and use "single precursor" which provides in a single molecule all the elements needed for the coating growth. Such an approach could allow to simplify the process complexity. But in the specific case of a carbide growth on a carbon surface, there is another possibility: the "reactive way", for which the carbon is provided by the substrate itself, one single gaseous precursor being thus necessary to transport silicon. This is the way we choose to optimize SiC layers on carbon based materials. The coating process is also modified with regard to a conventionnal CVD furnace. In fact we use a pack-cementation process. In such a process, the gaseous reactive species are generated in the deposition reactor, very close to the piece to be coated. In this work, the carbon substrate is plunged in a $\operatorname{SiC}(\alpha$ polytypes) $-\mathrm{SiO}_{2}$ ( $\alpha$-quartz) powders mixture. The porosity of this cement is about 65 volumic $\%$. Some authors [4-11] investigated the reaction path mechanism. Their results mainly differ with regard to the temperature and total pressure ranges used. In a previous paper [12] the correlation between thermogravimetric analysis (TGA) and thermochemical calculations allowed us to establish a reaction path for the reactive species formation. The global reaction proceeds via two stages in which oxygen plays an important role. During the first stage silica decomposes with respect to:

$$
\left.2 \mathrm{SiO}_{2}(\mathrm{~s}, \mathrm{l})-\cdots-\cdots+-\mathrm{SiO}_{\mathrm{g}} \mathrm{g}\right)+\mathrm{O}_{2}(\mathrm{~g})
$$

In a second step, gaseous oxygen diffuses to $\mathrm{SiC}$ particles and reacts according to:

$$
\mathrm{SiC}(\mathrm{s})+\mathrm{O}_{2}(\mathrm{~g})-\cdots----\mathrm{SiO}(\mathrm{g})+\mathrm{CO}(\mathrm{g})
$$

Both $\mathrm{SiO}_{2}$ decomposition (1) and $\mathrm{SiC}$ active oxidation (2) lead to the single gaseous silicon vector $\mathrm{SiO}$ and the overall reaction is described by:

$$
2 \mathrm{SiO}_{2}(\mathrm{~s}, \mathrm{l})+\mathrm{SiC}(\mathrm{s})------->3 \mathrm{SiO}(\mathrm{g})+\mathrm{CO}(\mathrm{g})
$$

These results are established in a vertical alumina hot wall reactor ( $25 \mathrm{~mm}$ in diameter) at temperatures ranging from 1400 to $1700{ }^{\circ} \mathrm{C}$. Experiments are performed with a $500 \mathrm{mg}$ mixture of silica and silicon carbide (with a great excess of $\mathrm{SiC}$ ) and without carbon substrate. Cement is set in a crucible ( $8 \mathrm{~mm}$ in diameter and $15 \mathrm{~mm}$ length). Total pressure is maintained at $104 \mathrm{kPa}$ by the means of a $18 \mathrm{l} / \mathrm{h}$ flow of argon and of a needle valve.

For the following experiments, the same conditions are used. Moreover, a carbon substrate, $2 \times 7.5 \times 10$ $\mathrm{mm}^{3}$ sized, is set in the powders mixture. Except particular mention, experiments are always performed with a vitreous carbon substrate (V25 grade - Le Carbone Lorraine).

\section{RESULTS AND DISCUSSION}

\subsection{Overall Chemical Reaction}

First results concern weight increase of the cemented piece versus temperature. An Arrhenius plot is shown in the figure 1 for temperature ranging from 1475 to $1650^{\circ} \mathrm{C}$ and for a cementation time of one hour. It may be reasonably assumed that this curve is linear and so an apparent activation energy $\mathrm{E}_{\mathrm{a}}=427 \pm 7 \mathrm{~kJ} \mathrm{~mol}^{-1}$ may be calculated for the reaction. 
This value is to compare with those of $466 \mathrm{~kJ} \mathrm{~mol}^{-1}$ [13] and $472 \mathrm{~kJ} \mathrm{~mol}^{-1}$ [10] obtained for the $\mathrm{C} \mathrm{(s)+}$ $\mathrm{SiO}(\mathrm{g})$ reaction. As usual, this high value of $\mathrm{E}_{\mathrm{a}}$ should indicate that the $\mathrm{SiC}$ formation is monitored by the surface chemical kinetics. In this case, this interpretation seems to be very hazardous. For packcementation, temperature does not only act on the coating reaction, but firstly on the cement reaction. $E_{a}$ is thus a "composite" energy that joins numerous phenomena and at least three solid-gas reactions: two are related to the $\mathrm{SiO}(\mathrm{g})$ formation as foresaid and one or more to the coating growth. This only $\mathrm{E}_{\mathrm{a}}$ value alone cannot allow us to determine the limiting step of the overall process. But some further informations will be described in the next subsections.

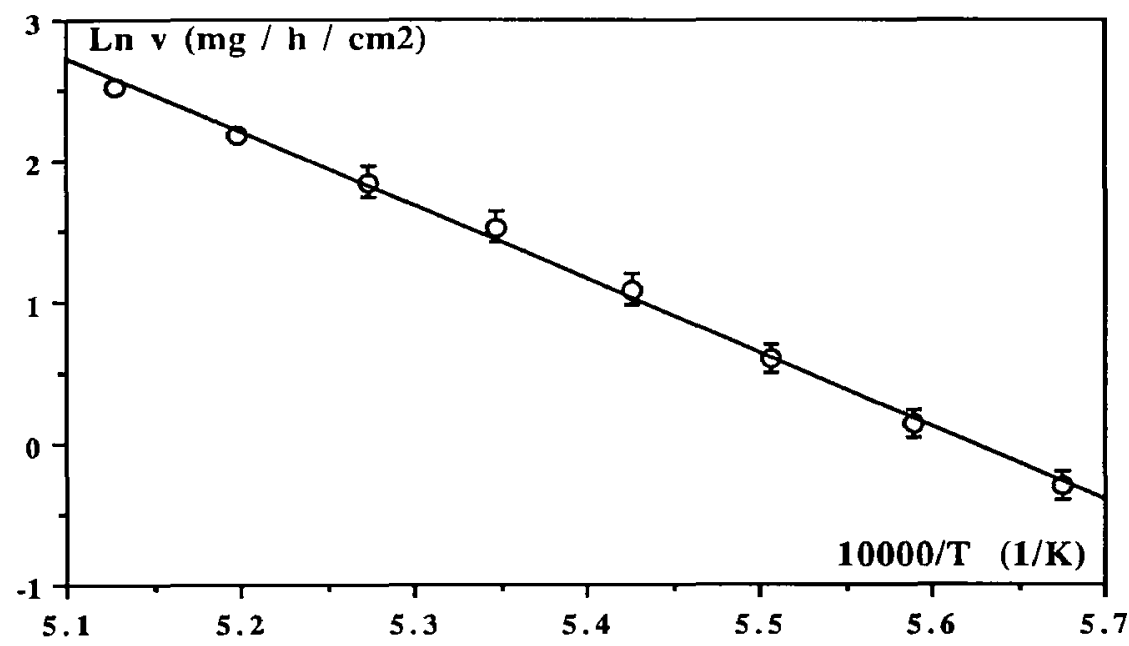

Figure 1: Armenius plot of the growth rate $v\left(\mathrm{mg} \mathrm{h}^{-1} \mathrm{~cm}^{-2}\right)$ versus the reciprocal temperature $\left(\mathrm{K}^{-1}\right)$

Density measurements of the cemented substrate are of special interest. They are performed on the piece constituted by the $\mathrm{SiC}$ layer and the remaining carbon of the substrate by the means of an helium pycnometer (Micromeritics - Accupyc 1330). From the density d of the coated substrate, it can be set:

$$
\frac{1}{d}=\frac{X_{S i C}}{d_{S i C}}+\frac{X_{C}}{d_{C}}
$$

$X_{S i C}, d_{S i C}, X_{C}$ and $d_{C}$ are the weight fraction and the density of the silicon carbide and the carbon substrate, respectively $\left(X_{S i C}+X_{C}=1\right)$. From the $X_{S i C}$ value it is then possible to compute $n_{C}$ over $n_{S i C}$ ratio, $n_{C}$ being the number of carbon moles consumed to produce $n_{S i C}$ moles of silicon carbide:

$$
\frac{n_{C}}{n_{S i C}}=\frac{\frac{m_{0}-m_{f} X_{C}}{M_{C}}}{\frac{m_{f} X_{S i C}}{M_{S i C}}}
$$

$m_{0}$ and $m_{f}$ are the weights of the uncoated and cemented piece, $M_{C}$ and $M_{S i C}$ are the molecular weights of carbon and silicon carbide, respectively. The vitreous carbon substrate exhibits a $d_{C}=1.44 \pm 0.01$. The density of the SiC coating has been measured on completely cemented substrate (no carbon remaining) and this leads to the value $\mathrm{d}_{\mathrm{SiC}}=3.246 \pm 0.013$. This value is slightly but significantly higher than the theoretical one $\left(d_{\beta-S i C}=3.21\right)$. At this time, wecan not explain this unexpected property and further analytical works will be needed to conclude. 
Nevertheless, the $n_{C} / n_{S i C}$ ratio is always close to 2 , which means that the overall reaction can be written:

$$
2 \mathrm{C}(\mathrm{s})+\mathrm{SiO}(\mathrm{g})-\ldots-\ldots \mathrm{SiC}(\mathrm{s})+\mathrm{CO}(\mathrm{g})
$$

This result quite agrees with chemical equilibrium calculations in the system $\mathrm{Si}-\mathrm{C}-\mathrm{O}$ [14], for temperature and total pressure under consideration in the present pack-cementation process.

\subsection{The Growth Interface}

Considering the equation (6), in the very first time of cementation, SiO reacts directly with the carbon substrate. But as soon as a SiC layer is formed, further growth needs chemical species diffusion through this layer. To explain the CO (g) escape from the cemented piece, carbon diffusion is necessary. Without any consideration about the real nature of the diffusing carbon species, this single diffusion could lead to the $\mathrm{SiC}$ growth. Therefore the growth interface should be located at the outer surface of the piece. Such a situation implicates vacancies in the substrate and should result in porosity appearence at the substrate-layer interface.

Another possibility could be for the silicon species to simultaneously diffuse from the free surface to the substrate. In this case, the growth interface should be located at the substrate-layer interface.

A way to determine which of these two phenomena prevails, is to look the substrate-layer motion with regard to the initial surface position. To do so, a marker experiment is performed which consists in partially coating the initial carbon substrate with an inert compound. This compound has to present specific properties and we thus choose iridium metal. There is no stable compound with carbon, no reaction with silicon for cementation conditions, the high melting point $(2727 \mathrm{~K})$ prevents from high vapour pressure, and thermal expansion coefficients are similar $\left(\alpha_{\mathrm{Ir}}=4.810^{-6} \mathrm{~K}^{-1}\right.$ at $1273 \mathrm{~K}, \alpha_{\text {vitreous } \mathrm{C}}=3.510^{-6} \mathrm{~K}^{-1}$ at $923 \mathrm{~K})$. A $2 \mu \mathrm{m}$ thick iridium partial layer is applied by sputtering on the carbon substrate which is then cemented. Figure 2 shows the failure face of this sample, observed by scanning electron microscopy (SEM).

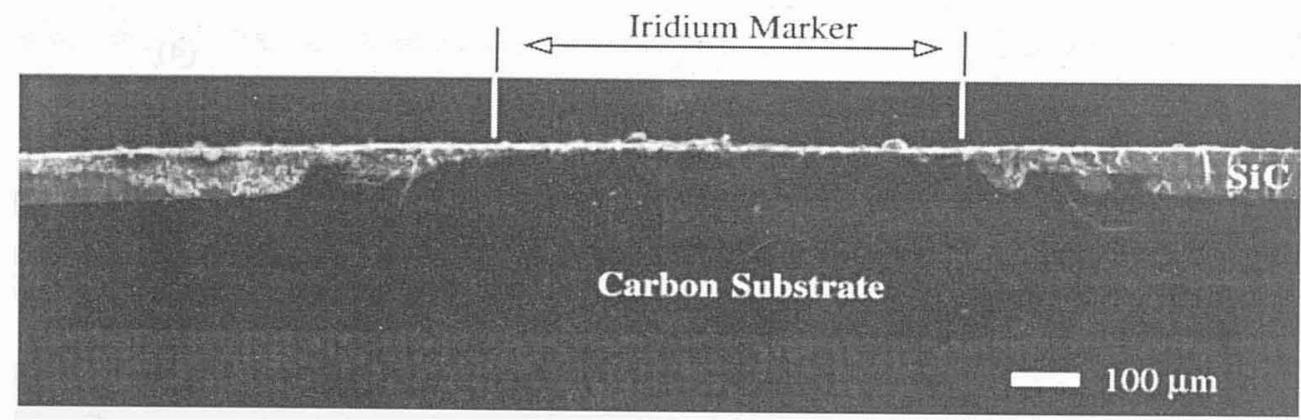

Figure 2: failure face (SEM) of a sample partially coated with iridium before cementation

Apart from the iridium coating, a $80 \mu \mathrm{m}$ thick SiC layer develops. No silicon carbide is observed at the marker level which permits to localize the initial surface. Some irregularities are scen on the interface profile, due to defects of the mask used to deposit the marker. Even at higher magnification, no evidence of porosity chain is observed. The growth interface seems then to be located at the substrate-SiC interface. 
Complementary proof is established in a different way. A carbon substrate is submitted to repeated cementations, according to the same experimental conditions of temperature $\left(1600^{\circ} \mathrm{C}\right)$, time $(1 \mathrm{~h})$ and so on. Between two successive cementations, the sample is weighted and the cement (powders mixture) is renewed. A failure face of such a sample is shown in figure 3. The weight increases are 14.9, 9.3, and 7.4 $\mathrm{mg}$ for the first, second and third cementation, respectively. The corresponding SiC thicknesses are 80,60, and $50 \mu \mathrm{m}$. The $14.9 \mathrm{mg}$ and $80 \mu \mathrm{m}$ values for the first cementation agree perfectly with the values obtained for a single cementation (the process is highly reproducible). This observation leads then to undoubtly establish that the growth interface is located at the substrate-SiC interface. The decrease in growth rate for the successive cementations points out a diffusion phenomenon. The cement being renewed, the outer surface conditions are identical for each run, what means that this decrease is due to the diffusion of carbon or silicon species through the SiC layer. This could explain the slightly decrease of the curve slope shown in figure 1 at high temperatures. The length of all experiments being the same $(1 \mathrm{~h})$, higher is the temperature, higher is the final thickness, and lower is the mean growth rate. Nevertheless this effect seems to be weak, in that the diffusion length is big (about $100 \mu \mathrm{m}$ ). The next section deals with the nature of diffusion through the silicon carbide coating.

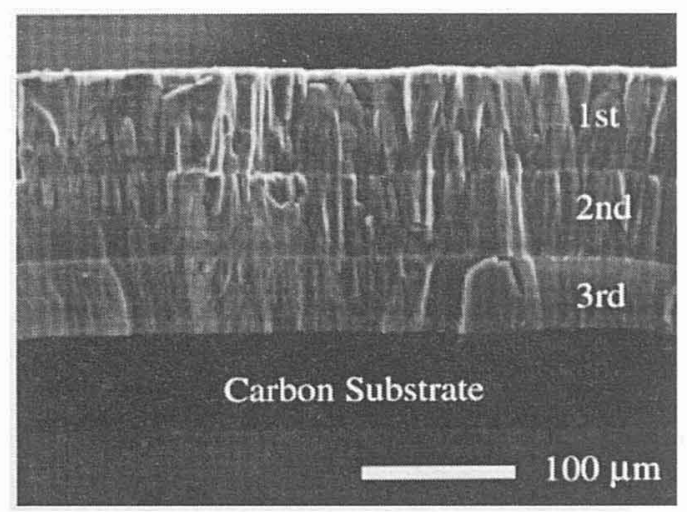

Figure 3: failure face (SEM) of a threc times cemented sample

\subsection{Diffusions in the Coating}

As foresaid, both silicon and carbon have to diffuse through the coating to allow further growth. In order to investigate the diffusion mechanism, an original approach is used. It consists in first coating the carbon substrate with a $2 \mu \mathrm{m}$ conventional chemical vapour deposited SiC layer (CVD SiC). This film is dense (measured density $=3.205$ ), and of the cubic type.

The next step is to submit this substrate to cementation. However, to easily compare the resulting cemented layer with the usual one, the CVD SiC layer is hollowed, or more exactly abraded. The outer surface of the resulting subtrate is then mainly CVD SiC coated and presents some circular zones (about 700 $\mu \mathrm{m}$ in diameter) where the carbon substrate is directly exposed.

After cementation, the piece is broken and the corresponding failure face is shown in figure 4.

The main observation is that cementation only occurs in areas where no CVD SiC coating exisis. On the contrary, no significant growth is seen beneath the CVD SiC, except in the very close vicinity of the hole. 
Nevertheless, CVD and cementation compounds have the same chemical nature. Therefore, the diffusion of the silicon species generated from the cement seems to be impossible through the CVD SiC. The more convenient explanation is that those $\mathrm{SiC}$ phases are structurally strongly different. And the most probable reason for such a difference concerns the respective "density", or more appropriate, the respective porosity of these silicon carbides. CVD SiC is known to be "dense", porosity free. At this point one can rationally assume that cementation layer is porous. The growth rate could be another indication for this. As written before this rate is about $80 \mu \mathrm{m} \mathrm{h}^{-1}$ at $1600^{\circ} \mathrm{C}$ and involves diffusion phenomena. Let forget a few moments the exact slower diffusing species and its nature, and only consider the basic mechanism. Two possibilities have to be considered: solid state and gaseous diffusions. The silicon and carbon self-diffusion coefficients in silicon carbide lattice are $9.310^{-14}$ and $1.2110^{-11} \mathrm{~cm}^{2} \mathrm{~s}^{-1}$ at $2000^{\circ} \mathrm{C}$, respectively [15]. For most systems, gas diffusion coefficients are few $\mathrm{cm}^{2} \mathrm{~s}^{-1}$. Our computations [16-17] lead to 4.4 and $3.0 \mathrm{~cm}^{2} \mathrm{~s}^{-1}$ for $\mathrm{CO}(\mathrm{g})$ and $\mathrm{SiO}(\mathrm{g})$ diffusivity in argon gas at $1600^{\circ} \mathrm{C}$ and $104 \mathrm{kPa}$. The substrate-layer interface is a planar and constant composition one and thus, its displacement $X$ accords to the formula $X(m)=2 \gamma \sqrt{D\left(m^{2} s^{-1}\right) t(s)}[18]$. Unfortunately, the $\gamma$ value varies a lot depending on the system, the $D$ coefficient can be greatly affected (several orders of magnitude) by grains boudaries effects for solid state diffusion, and by tortuosity effects for gaseous diffusion. Direct evidence of porosity is thus needed to definitively establish the gaseous diffusion growth mechanism.

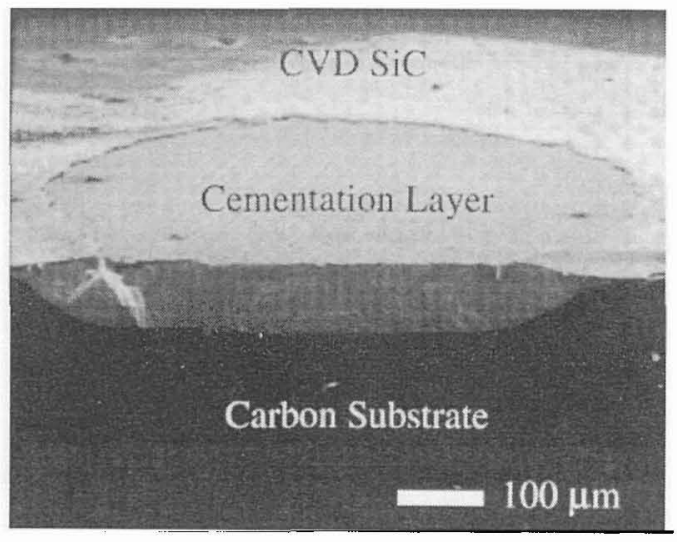

Figure 4: failure face (SEM) of a cemented vitreous carbon substratc. The picce is preliminarly coatcd with a $2 \mu \mathrm{m}$ thick CVD SiC layer, which is locally mechanically abraded

\subsection{Characterization of the Cementation Layer}

$\mathrm{X}$-ray diffraction first establishes that the cementation layer is mainly of the cubic type ( $\beta$-SiC). But one additionnal line $\left(\mathrm{d}_{\mathrm{ad}}=2.65 \AA\right)$ is clearly detected near the (111) line of the cubic structure $\left(\mathrm{d}_{111}=2.51 \AA\right)$. This $2.65 \AA$ value is characteristic of hexagonal polytypes. In the case of CVD SiC this line is often associated with stacking faults of $\alpha$-type in the cubic structure [19-20]. At this time, we can not determine whether such aleatory faults or polytypes mixture is the reason for this line. It will be interesting to further investigate this question. Through the thickness of the coating the relative intensity of this $d_{a d}$ increases from about $3 \%$ of the greater line intensity (free surface) to about $16 \%$ (substrate-layer interface).

Transmission electron microscopy (TEM) is used to evidence the porosity of the cementation layer. It appears in figure 5 that silicon carbide is constituted by very fine cristallites. The micrography plane is parallel to the substrate-layer interface. Higher magnification allows to measure the mean size of the cristallites around 100$) \mathrm{nm}$ in diameter. The porosity mean size is about $20-30 \mathrm{~nm}$. 
Nevertheless, CVD and cementation compounds have the same chemical nature. Therefore, the diffusion of the silicon species generated from the cement seems to be impossible through the CVD SiC. The more convenient explanation is that those $\mathrm{SiC}$ phases are structurally strongly different. And the most probable reason for such a difference concerns the respective "density", or more appropriate, the respective porosity of these silicon carbides. CVD SiC is known to be "dense", porosity free. At this point one can rationally assume that cementation layer is porous. The growth rate could be another indication for this. As written before this rate is about $80 \mu \mathrm{m} \mathrm{h}^{-1}$ at $1600^{\circ} \mathrm{C}$ and involves diffusion phenomena. Let forget a few moments the exact slower diffusing species and its nature, and only consider the basic mechanism. Two possibilities have to be considered: solid state and gaseous diffusions. The silicon and carbon self-diffusion coefficients in silicon carbide lattice are $9.310^{-14}$ and $1.2110^{-11} \mathrm{~cm}^{2} \mathrm{~s}^{-1}$ at $2000^{\circ} \mathrm{C}$, respectively [15]. For most systems, gas diffusion coefficients are few $\mathrm{cm}^{2} \mathrm{~s}^{-1}$. Our computations [16-17] lead to 4.4 and $3.0 \mathrm{~cm}^{2} \mathrm{~s}^{-1}$ for $\mathrm{CO}(\mathrm{g})$ and $\mathrm{SiO}(\mathrm{g})$ diffusivity in argon gas at $1600^{\circ} \mathrm{C}$ and $104 \mathrm{kPa}$. The substrate-layer interface is a planar and constant composition one and thus, its displacement $X$ accords to the formula $X(m)=2 \gamma \sqrt{D\left(m^{2} s^{-1}\right) t(s)}[18]$. Unfortunately, the $\gamma$ value varies a lot depending on the system, the $D$ coefficient can be greatly affected (several orders of magnitude) by grains boudaries effects for solid state diffusion, and by tortuosity effects for gaseous diffusion. Direct evidence of porosity is thus needed to definitively establish the gaseous diffusion growth mechanism.

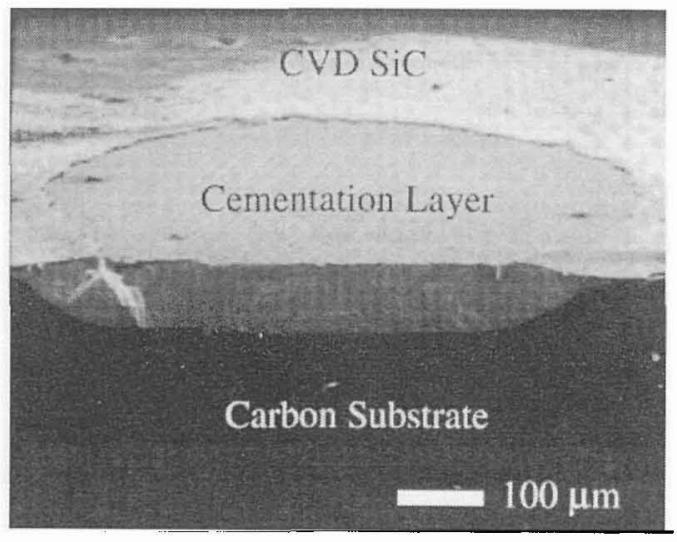

Figure 4: failure face (SEM) of a cemented vitreous carbon substratc. The picce is preliminarly coatcd with a $2 \mu \mathrm{m}$ thick CVD SiC layer, which is locally mechanically abraded

\subsection{Characterization of the Cementation Layer}

$\mathrm{X}$-ray diffraction first establishes that the cementation layer is mainly of the cubic type ( $\beta$-SiC). But one additionnal line $\left(\mathrm{d}_{\mathrm{ad}}=2.65 \AA\right)$ is clearly detected near the (111) line of the cubic structure $\left(\mathrm{d}_{111}=2.51 \AA\right)$. This $2.65 \AA$ value is characteristic of hexagonal polytypes. In the case of CVD SiC this line is often associated with stacking faults of $\alpha$-type in the cubic structure [19-20]. At this time, we can not determine whether such aleatory faults or polytypes mixture is the reason for this line. It will be interesting to further investigate this question. Through the thickness of the coating the relative intensity of this $d_{a d}$ increases from about $3 \%$ of the greater line intensity (free surface) to about $16 \%$ (substrate-layer interface).

Transmission electron microscopy (TEM) is used to evidence the porosity of the cementation layer. It appears in figure 5 that silicon carbide is constituted by very fine cristallites. The micrography plane is parallel to the substrate-layer interface. Higher magnification allows to measure the mean size of the cristallites around 100$) \mathrm{nm}$ in diameter. The porosity mean size is about $20-30 \mathrm{~nm}$. 
As foresaid in section 2.1, helium pycnometry density is close to the theoretical one. That means the overall porosity is an open porosity. This is corroborated by adsorption and desorption isotherms measurements (BET): a $7.0 \mathrm{~m}^{2} \mathrm{~g}^{-1}$ specific surface area is calculated, which is a very high value for a "massive" coating. TEM cross section observation indicates that this open porosity looks like nano channels from the free surface to the interface. We can then assume that the diffusion growth mechanism is a gaseous one: $\mathrm{SiO}(\mathrm{g})$ diffuses from the cement to the carbon substrate by these nano channels, reacts to form $\mathrm{SiC}(\mathrm{s})$ and $\mathrm{CO}(\mathrm{g})$, and this latter diffuses backwards to the outer surface.

BET isotherms, apparent density measurements, and TEM imaging allow to estimate the coating porosity. It is about 25 to 30 vol\%. This value is obviously high and concerns the only vitreous carbon substrate. The porosity strongly depends on the carbonaceous substrate used. The explanation of this particular behaviour will not be discussed here and will be reported in an impending paper [14].

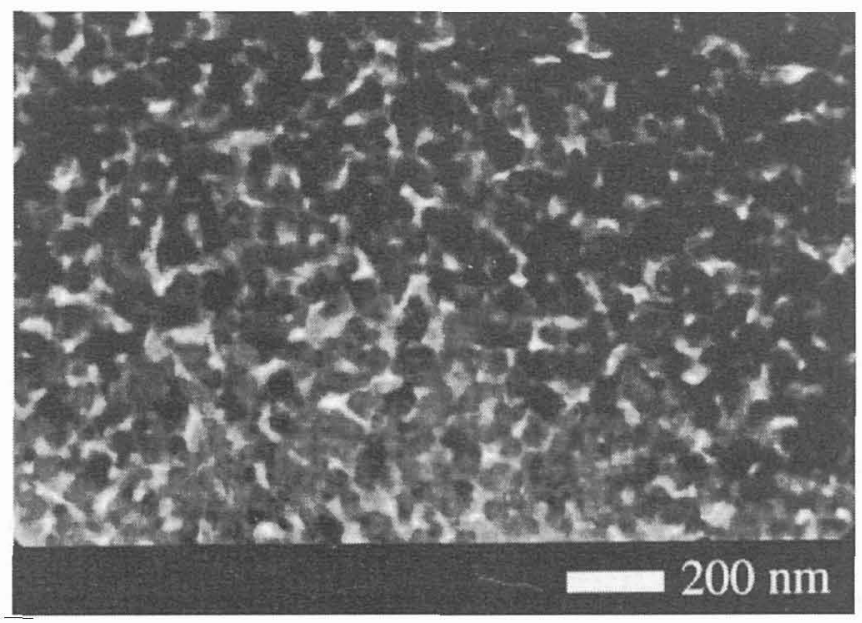

Figure 5: TEM micrography of a cementation layer (section parallel to the sample surface)

\section{CONCLUSIONS}

Silicon carbide coatings are performed on carbon materials by a pack-cementation process. The silicon precursor is silicon monoxide $\mathrm{SiO}(\mathrm{g})$ which originates from a $\mathrm{SiC}-\mathrm{SiO}_{2}$ powders mixture and the substrate provides the carbon. The growth interface is identified as the substrate-layer interface. The reaction products are $\beta$-SiC and $\mathrm{CO}(\mathrm{g})$ as a by-product. The growth leads to a finely porous film in which occur the gaseous diffusions of $\mathrm{SiO}(\mathrm{g})$ to the substrate and of $\mathrm{CO}(\mathrm{g})$ backwards. Vitreous carbon cementation results in a 25 to $30 \mathrm{vol} \%$ porous layer. The overall porosity is open and preferentially oriented perpendicular to the sample surface as nano channels. These latter are 20 to $30 \mathrm{~nm}$ sized.

The growth mechanism and the great porosity should enhance both adhesion and thermal shock resistance of the SiC layer. It should be an adequate interphase between carbon materials and an outer oxidation resistant coating. 


\section{Acknowledgments}

This research was supported in part by the Aerospatiale (contract $n^{\circ} 43-E 2-245205-32126$ ) and the Centre National de la Recherche Scientifique (contract $n^{\circ} 710214$ ). We have greatly appreciated the support of J.F. Jamet and B. Capdepuy and the guidance of P. Delhaes, P. Lespade and G. Rousseau.

\section{References}

[1] Stinton D. P., Bessman T. M., Lowden R. A., American Ceramic Society Bulletin, Vol. 67, N², (1988), 350-355

[2] Derré A., Ducarroir M., Teyssandier F., Revue Internationale des Hautes températures et Réfractaires, Vol. 29, (1994), 11-35

[3] Schlichting J., Powder Metallurgy International, Vol. 12, $N^{\circ} 3,(1980), 141-147$

[4] Elmer T. H., U.S. Atomic energy, NEPA 1770, (1950)

[5] Yudin B. F., Makarova N. L., Zhurnal Prikladnoi Khimiu, Vol. 41, N 1, (1968), 33-39

[6] Pultz W. W., Herlt W., Transactions of the Faraday Society, Vol. 13, No 71, (1966), 499-504

[7] Borisov V. G., Yudin B. F., Ogneupory, Vol. 3, (1968), 37-40

[8] Komolgorov Y. K., Rogailin M. I., FarberovI. L.,Khimia Tverdogo Toplia, Vol. 9, N$^{\circ}$ 1, (1975), 149. 153

[9] Miller P. D., Lee J. G., Cutler I. B., Joumal of the American Ceramic Society, Vol. 62, N 3, (1979), 147-149

[10] Filsinger D., Bourrie D. B., Journal of the American Ceramic Society, Vol. 73, N$^{\circ} 6,(1990), 1726$ 1732

[11] Jacobson N. S., Opila E. J., Metallurgical Transactions A, Vol. 75, N 6, (1993), 1603-1611

[12] Paccaud O., Derré A., "Silicon carbide coating for carbon-carbon composites produced by a high temperature pack-cementation process", Proceedings of the Eight Cimtec - Forum on New Materials Advances in Inorganic Films \& Coatings, Florence - Italy - June 28 - July 4, (1995), in press

[13] Kennedy P., North B., Proceedings of the British Ceramic Society, Vol. 33, (1983), 1-15

[14] Paccaud O., Derré A., to be submitted

[15] Gmelin L., Gmelin handbook of inorganic chemistry, Supplement Vol. B2, Silicon Carbide Part 1, 8th edition, (Springer-Verlag, Berlin, 1984)

[16] Reid R. C., Prausnitz J. M., Poling B. E., The properties of gases and liquids, 4th edition, (Mc Graw-Hill Book Company, New York, 1987)

[17] Rosner D. E., Transport Process Chemical Reacting Flow Systems, (Butterworth Publishers, Stoneham, M. A., 1986)

[18] Philibert J., Diffusion et transport de Matière dans les solides, (Les Editions de Physique, Les Ulis, France, 1990)

[19] Schamm S., Mazel A., Dorignac D., Sevely J., Microscopy Microanalysis Microstructure, Vol. 2, N $1,(1991), 59-73$

[20] Schamm S., Mazel A., Dorignac D., Sevely J., "Observation en microscopie électronique a haute résolution du polytypisme de $\mathrm{SiC}$ dans la matrice d'un composite $\mathrm{SiC} / \mathrm{SiC}$ ", Actes du Colloque Matériaux Composites pour Applications à Haute Température, Bordeaux, France, 29-30 Mars, R. Naslain, J. Lamalle et J. L. Zulian éds, (AMAC/CODEMAC, Bordeaux, France, 1990), 207-219 